\title{
Quantitative electroencephalographic changes and hippocampal atrophy in diabetic patients with mild cognitive impairment in Ismailia region
}

\author{
Ahmed Abo hagar ${ }^{1}$, Yossri Ashour ${ }^{1}$, Reda Abd El-Razek ${ }^{1,2^{*}}$, Mohamed Elsamahy ${ }^{1}$ and Osama Shehab ${ }^{1}$
}

\begin{abstract}
Background: Cognitive decline could start or get worse among elderly patients with diabetes mellitus more than elderly without diabetes mellitus. So, those diabetic elderly patients have more risk to develop Alzheimer's disease and vascular dementia.

Patients and Methods: This study included 48 elderly, grouped into three equal groups. First group included patients with diabetes mellitus and cognitive impairment. Second group included patients with diabetes mellitus and no cognitive impairment. The last group included the controls. Evaluation through Mini Mental State Examination, MRI brain, and Quantitative Electroencephalography (QEEG) recording was done for every studied elderly.

Results: MRI finding revealed that hippocampal atrophy was significantly more prevalent among diabetic patients with mild cognitive impairment (MCI) (37.5\%). The QEEG showed increase in the distribution of alpha 1 (low alpha) waves among control and diabetic patients without $\mathrm{MCl}$ groups, while there was an increase in the distribution of alpha 2 (high alpha) among diabetic patients with MCI. The QEEG results revealed increased alpha 2/alpha 1 ratio among patients with hippocampal atrophy.

Conclusions: Type 2 DM was suggested to increase the risk of cognitive impairment. The cognitive impairment in patients with diabetes mellitus was associated with changes in hippocampal volume and QEEG changes.
\end{abstract}

Keywords: Diabetes mellitus, Mild cognitive impairment, Hippocampal atrophy, QEEG

\section{Background}

Diabetes mellitus is a common disease known to have adverse effects on all systems of the body (Kodl and Seaquist 2008). Cognitive decline could start or get worse among elderly patients with diabetes mellitus more than elderly without diabetes mellitus. So, those diabetic elderly patients have a higher risk of developing Alzheimer's disease and vascular dementia (Das et al. 2007). Mild cognitive impairment is a stage between normal cognitive changes with aging and very early dementia (Petersen and Negash 2008). Attention and

\footnotetext{
* Correspondence: Dr.reda_abdelrazek@yahoo.com

'Department of Neuropsychiatry, Suez Canal University, Ismailia, Egypt

${ }^{2}$ Department of Neurology, Faculty of Medicine, Suez Canal University, Ismailia, Egypt
}

(c) The Author(s). 2018 Open Access This article is distributed under the terms of the Creative Commons Attribution 4.0 International License (http://creativecommons.org/licenses/by/4.0/), which permits unrestricted use, distribution, and reproduction in any medium, provided you give appropriate credit to the original author(s) and the source, provide a link to the Creative Commons license, and indicate if changes were made. memory formation take place in the hippocampus. The hippocampus is the main source of rhythmic activity in EEG (Tsanov et al. 2011). It is widely accepted that the cerebral EEG rhythms reflect underlying brain network activity. So, the modifications in these rhythms could be an early sign of Alzheimer's disease. Specifically, the study of alpha rhythm could be a satisfying measurement for the relationship between the structure and the function of these brain networks (Ingber and Nunez 2011).

\section{Aim of the work}

The aim of this work was to assess the effect of diabetes mellitus on cognitive functions, through assessing quantitative EEG changes and hippocampal atrophy in diabetic patients with mild cognitive impairment.

\section{SpringerOpen}




\section{Patients and methods}

This is a case-control study, including 32 diabetic patients with variable levels of education with at least 8 years of education selected by the attendants in the neuropsychiatry outpatient clinic in Suez Canal University Hospital, Ismailia, Egypt. Patients were subdivided into one group of patients with diabetes mellitus and cognitive impairment and a second group which included patients with diabetes mellitus and no cognitive impairment. The inclusion criteria were the following: controlled diabetic patients with type 2 diabetes, patient aged 55-85 years old, complaint by the patient or report by a relative of memory or other cognitive disturbances, patients with minimal or no depression (according to Beck Depression Inventory) (Beck et al. 1996), and the Arabic translated form of Mini-Mental State Examination (MMSE) with score of 24-27/30 (American Psychiatric Association (APA) 2013).

The exclusion criteria were the following: illiterate individuals or less than 8 years of education, any patient with disturbed conscious level, history or neurological signs of vascular or degenerative disorder, other psychiatric diseases, dementia (MMSE score below 24), epilepsy, patient with moderate or severe depression (according to Beck Depression Inventory), and using psychoactive drugs which included acetylcholinesterase inhibitors and included drugs that enhance brain cognitive functions or bias EEG activity. Also, the systemic diseases that could affect cognitive function and the history or current intake of alcohol or drug addiction were excluded.

Another 16 age-, sex-, and education-matched healthy subjects were included as a control group. The study was approved by the Suez Canal Faculty of Medicine Ethical Committee. Written, informed consent was obtained from all persons before inclusion in the study.

\section{Methods}

All subjects underwent the following:

A. Clinical assessment including thorough history taking, full general, and neurological examination.

B. Routine laboratory investigations: fasting, postprandial blood sugar level and HBA1C, lipid profile, liver, kidney and thyroid function tests, complete blood count, ESR, uric acid, and $\mathrm{Na}, \mathrm{K}$ and calcium levels. These tests were done for exclusion of any systemic diseases.

C. Clinical diagnosis of mild cognitive impairment (MCI) according to DSM-V criteria (American Psychiatric Association (APA) 2013).
D. Cognitive assessment using the Mini Mental State Examination (MMSE) (Folstein et al. 1975).

\section{Measurement of the hippocampus}

Coronal and sagittal magnetic radiographic volumetric scan with high-resolution $\mathrm{T} 1$ weight intensity was done. The Philips Acheiva scanner 1.5 T, Netherlands (Holland), was used. The used technique was the gradient echo 3D with repetition (TR) of $20 \mathrm{~ms}$ and echo (TE) of $5 \mathrm{~ms}$. The used Flip Angle was 30 to view a field of $220 \mathrm{~mm}$. The slice thickness was at 1 . $3 \mathrm{~mm}$ and acquisition matrix of $256 \times 256$. The hippocampus was measured including the fimbria but with exclusion of the rostral gray matter. The hippocampal tail was included as seen by its oval shape just medial and caudally to the lateral ventricles (Pruessner et al. 2000). It was carried out at Suez Canal University MRI center.

The volume of the hippocampus was calculated by the summation of measured volumes of both right and left hippocampus. The mean value of hippocampus volume among normal elderly was $5.75 \mathrm{~cm}^{3}$ with standard deviations of $\pm 1.1 \mathrm{~cm}^{3}$ (Moretti et al. 2007). The cutoff value was presented using two standard deviation from the mean $\left(3.55 \mathrm{~cm}^{3}\right)$. So, the atrophy of hippocampus was considered in elderly with hippocampus volume measuring less than that value.

\section{Digital EEG examination}

Digital EEG was recorded utilizing E-Series EEG/PSG system (c) Compumedics Limited 2004, Australia. Placing the electrodes was done according to the International 10-20 system, and ear lobe electrodes were used as reference, with a ground electrode on the forehead. Impedance was kept below $10 \mathrm{kohm}$. The high-frequency filter was $70 \mathrm{~Hz}$, the time constant was 0.3 , and the paper speed was $30 \mathrm{~mm} / \mathrm{s}$. The investigation was carried out while the patient was recumbent in supine position in semi-dark room. Recording was carried out for about 20 min with 3-min hyperventilation and intermittent photic stimulation as provocative techniques.

The EEG records were visually assessed. Five artifacts' free epochs while awake and resting were selected for QEEG, each epoch of 10-s duration. The relative powers of 19 electrodes (Fp1, Fp2, F7, F8, F3, F4, C3,C4, T3, T4, T5, T6, P3, P4, O1, O2, Fz, Cz, and Pz) were studied in the following frequency bands: delta $(0.5$ to $<4 \mathrm{~Hz})$, theta $(4$ to $<8 \mathrm{~Hz})$, alpha $1(8$ to $<11.0 \mathrm{~Hz})$, alpha $2(11$ to $<14 \mathrm{~Hz}$ ), beta $1(14$ to $<25 \mathrm{~Hz}$ ), and beta $2(25$ to $35 \mathrm{~Hz}$ ). The relative power was the percentage of the power of a given frequency band compared to the sum of the power of all frequency bands (Sharbrough et al. 2002). 


\section{Statistical analysis}

Collected data were processed using SPSS IBM SPSS statistics (version 22.0, 2013; IBM Corp. Armonk, New York, USA). Quantitative data were presented as means \pm SD. On the other hand, qualitative data were presented as numbers and its percentages. The used statistical tests for significance were the following: the one-way ANOVA to test the differences between groups and the chi-squared test in testing significance of difference between qualitative data. Pearson correlation coefficient $(r)$ was used to measure correlation between quantitative variables. A probability value $(P$ value) of less than 0.05 was considered as statistically significant. A probability value ( $P$ value) of less than 0.01 was considered statistically highly significant.

\section{Results}

\section{Demographic data}

This study was carried out on 48 subjects divided into three groups, each one containing 16 subjects. The first group consisted of diabetic patients with mild cognitive impairment, and their age ranged between 55 and 80 years with a mean $(63.75 \pm 6.83 \mathrm{SD})$; there were seven males (43. $8 \%$ ) and nine females (56.3\%). The second group consisted of diabetic patients without cognitive impairment. Their age ranged between 55 and 73 years with a mean $(62.18 \pm$ $5.03 \mathrm{SD})$; there were eight males (50\%) and eight females (50\%). The third group was the control group; their age ranged between 55 and 71 years with a mean $(62.25 \pm 4.87$ $\mathrm{SD})$. No statistically significant difference was detected between groups as regards age and sex $(P>0.05)$.

\section{Results of cognitive assessment}

On comparing the results of MMSE of the three groups, statistically significant lower results were found in DM with MCI group when compared to other groups $(P=0.001)$ (Table 1).

\section{Results of brain imaging}

Hippocampal atrophy was distributed significantly among DM with MCI group in comparison to other groups $(P=0.01)$ (Table 2$)$.

Table 1 The results of cognitive assessment among the study groups

\begin{tabular}{lllll}
\hline & DM with MCI & DM without MCI & Control group & ANOVA test \\
& Mean \pm SD & Mean \pm SD & Mean \pm SD & $P$ value \\
& Min-Max & Min-Max & Min-Max & \\
\hline MMSE & $25.5 \pm 0.51$ & $28.56 \pm 0.81$ & $28.62 \pm 0.88)$ & $0.001^{* *}$ \\
& $(25-26)$ & $(28-30)$ & $(28-30)$ & \\
\hline
\end{tabular}

DM diabetes mellitus, $M C I$ mild cognitive impairment, $S D$ standard deviation, Min minimum, Max maximum, MMSE Mini Mental State Examination **Statistically highly significant
Table 2 The distribution of hippocampal atrophy among the study groups

\begin{tabular}{lllll}
\hline & $\begin{array}{lll}\mathrm{DM} \text { with } \\
\mathrm{MCl}\end{array}$ & $\begin{array}{l}\mathrm{DM} \text { without } \\
\mathrm{MCl}\end{array}$ & $\begin{array}{l}\text { Control } \\
\text { group }\end{array}$ & $\begin{array}{l}\text { Chi-squared } \\
\text { test } \\
P \text { value }\end{array}$ \\
\hline Hippocampal atrophy & $6(37.5 \%)$ & $2(12.5 \%)$ & $0(0.0 \%)$ & $0.01^{* *}$ \\
\hline $\begin{array}{l}{ }^{* *} \text { Statistically highly significant } \\
\text { M diabetes mellitus, } \mathrm{MCl} \text { mild cognitive impairment }\end{array}$ & & \\
\end{tabular}

\section{Results of QEEG}

Predominance of alpha 2 was significantly higher among DM with MCI group in comparison to other groups with a mean $30.8 \pm 12.24(P=0.01)$, and alpha 1 was significantly lower among DM with $\mathrm{MCI}$ group in comparison to other groups with a mean $20.42 \pm$ $11.87(P=0.001)$ while theta, delta, and beta waves was found to be insignificant (Table 3 ).

Alpha 2/alpha 1 power ratio was distributed significantly among DM with MCI group in comparison to other groups $(P=0.01)$ (Table 4$)$ (Fig. 1 ).

Significant relationship was found between alpha 2/alpha 1 ratio and hippocampal atrophy among $\mathrm{DM}$ with $\mathrm{MCI}$ group in comparison to other groups $(P<0.001)$ (Fig. 2).

There was a high statistically significant positive correlation between hippocampal atrophy and alpha 2/alpha 1 ratio among DM with MCI group, where correlation coefficient $(r)=0.535$ and $P=0.001$ respectively (Table 5 ).

\section{Discussion}

Previous studies support the view that individuals with diabetes are at an increased risk for developing cognitive impairment (Allen et al. 2004) and dementia (Biessels et al. 2006). These studies found indicators for the associations between MCI and type 2 diabetes mellitus. Moreover, another longitudinal cohort study emphasized the association of type 2 diabetes mellitus with so called amnestic MCI among the population who developed both $\mathrm{AD}$ and vascular pathology, but with weak association with nonamnestic MCI (Biessels

Table 3 The relative power of all frequency bands among the study groups

\begin{tabular}{lllll}
\hline & $\begin{array}{l}\text { DM with MCI } \\
\text { Mean } \pm \text { SD }\end{array}$ & $\begin{array}{l}\text { DM without MCI } \\
\text { Mean } \pm \text { SD }\end{array}$ & $\begin{array}{l}\text { Control group } \\
\text { Mean } \pm \text { SD }\end{array}$ & $\begin{array}{l}\text { ANOVA test } \\
P \text { value }\end{array}$ \\
\hline Delta & $3.53 \pm 0.57$ & $3.42 \pm 0.41$ & $3.68 \pm 0.68$ & 0.40 \\
Theta & $22.87 \pm 3.04$ & $21.54 \pm 3.77$ & $21.26 \pm 3.85$ & 0.40 \\
Alpha 1 & $20.44 \pm 11.87$ & $31.06 \pm 12.70$ & $37.68 \pm 5.58$ & $0.001^{* *}$ \\
Alpha 2 & $30.80 \pm 12.24$ & $20.42 \pm 11.78$ & $17.18 \pm 4.40$ & $0.01^{* *}$ \\
Beta & $25.75 \pm 1.46$ & $24.53 \pm 0.68$ & $24.17 \pm 1.95$ & 0.33 \\
\hline
\end{tabular}

$D M$ diabetes mellitus, $M C I$ mild cognitive impairment, $S D$ standard deviation **Statistically highly significant 
Table 4 The distribution of alpha 2/alpha 1 ratio among the study groups

\begin{tabular}{lllll}
\hline & $\begin{array}{l}\mathrm{DM} \text { with } \\
\mathrm{MCl}\end{array}$ & $\begin{array}{l}\mathrm{DM} \\
\text { without } \\
\mathrm{MCl}\end{array}$ & $\begin{array}{l}\text { Control } \\
\text { group }\end{array}$ & $\begin{array}{l}\text { ANOVA test } \\
P \text { value }\end{array}$ \\
\hline Alpha 2/alpha 1 ratio & $2.6 \pm 2.15$ & $1.34 \pm 1.52$ & $1.0 \pm 0.86$ & $0.01^{* *}$
\end{tabular}

Alpha 2/alpha 1 power ratio was expressed as mean \pm SD

$D M$ diabetes mellitus, $\mathrm{MCl}$ mild cognitive impairment

**Statistically highly significant

et al. 2007). EEG is not a new idea to be used as an early detection for cognitive decline. But still, EEG is unable to meet the National Institute on Aging Consensus Conference (1998) ideal parameters to be considered as a reliable biomarker. On the other hand, QEEG stood to debate those parameters with the facts of being a cost-effective, noninvasive technique for the identification of the earliest signs of brain dysfunction in patients with evolving dementia or even MCI. That will give the opportunity for early intervention and better chance for therapy to these patients (Prichep 2007). Another study adopted the same concept of considering electroencephalogram as an ideal noninvasive and economic procedure (Rossini et al. 2006).

The current study showed predominance of hippocampal atrophy among DM with MCI group with significant statistical difference $(P<0.05)$, while it was $12.5 \%$ of diabetic patient without MCI and $0.0 \%$ in normal control group. That was supported by other studies (Moretti et al. 2011; Frisoni 2012; Albert et al. 2011; McKhann et al. 2011).

In the current study, peak power frequency of alpha 2 was found high with predominance with hippocampal atrophy among DM with MCI group. That was supported by other studies (Moretti et al. 2011; Frisoni 2012). O’Donnell and Grace (1995) explained that
Table 5 Correlation between alpha 2/alpha 1 ratio and hippocampal atrophy among DM with $\mathrm{MCl}$ group

\begin{tabular}{lll}
\hline & Alpha 2/alpha 1 ratio & \\
\cline { 2 - 3 } & Correlation coefficient $(r)$ & $P$ value \\
\hline Hippocampal atrophy & $0.535^{*}$ & $0.001^{* *}$ \\
\hline
\end{tabular}

DM diabetes mellitus, $\mathrm{MCl}$ mild cognitive impairment

*Significant $r$ (correlation coefficiency) $>0.5$

**Correlation is highly significant at $<0.01$

predominance of synchronized alpha 2 bands over the frontal, temporal, and parietal regions is due to a progressive recruitment of many other cortical areas that involve wider cortico-thalamic re-entry loops. They specified the loop of the frontal-midline thalamic nuclei. This explanation was confirmed by Nicolelis and Fanselow (2002) and Klimesch et al. (2007) who considered the increase in the alpha power to be due to hyperpolarization at thalamic level.

The current study found significant predominance of alpha 1(low alpha) among subjects without cognitive impairment, and that was in agreement with that reported by Jelic et al. (2000) and considered these changes as a predictor of future conversion from $\mathrm{MCI}$ to AD. Moreover, Klimesch et al. (2003) stated that induction of large alpha 1 power by neurofeedback training or repetitive transcranial magnetic stimulation (rTMS) at alpha frequency range is typical for good memory performance under normal situations enhancing the cognitive performance.

That also was confirmed by Holschneider et al. (1998) and Sarter and Bruno (1997, 1999, 2000) who reported that the efferent projections of the forebrain are the main providers of the low alpha power. They regarded that to the cholinergic tone of the base of cortex especially in the nucleus basalis of Meyner. But some studies actually considered that

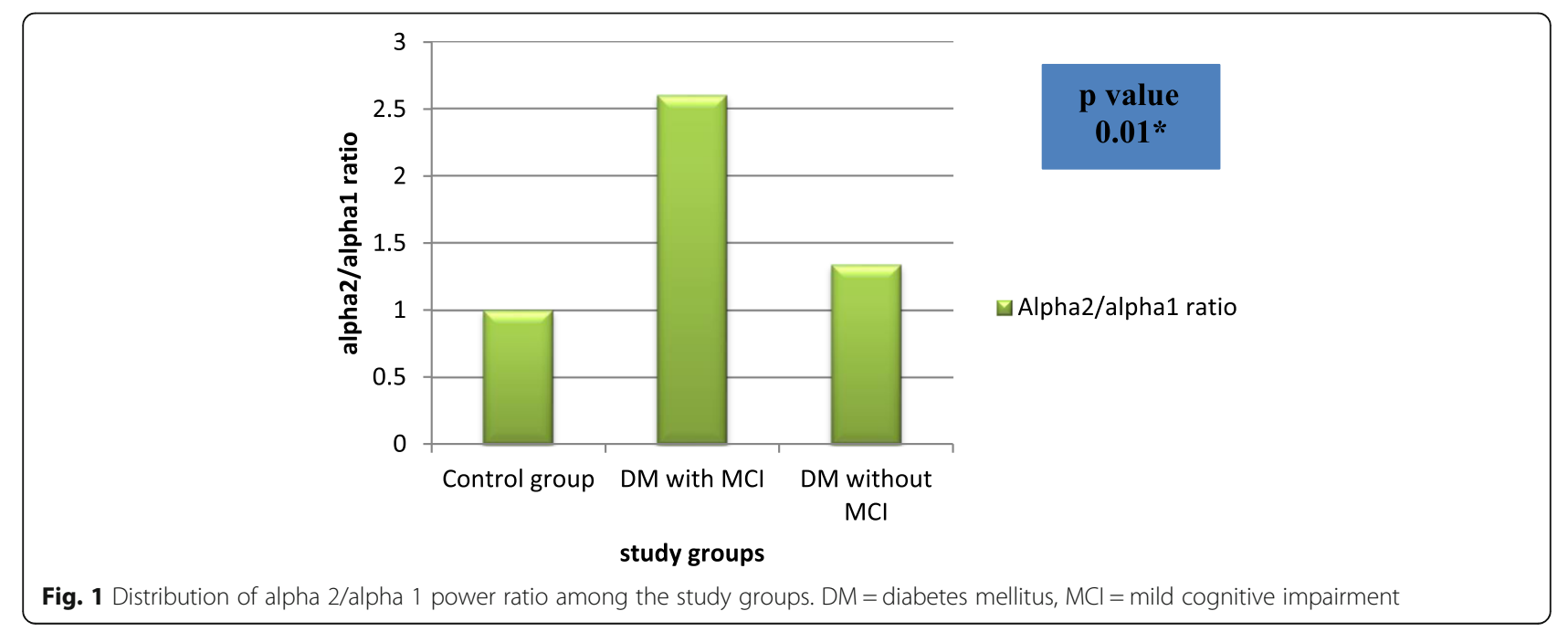




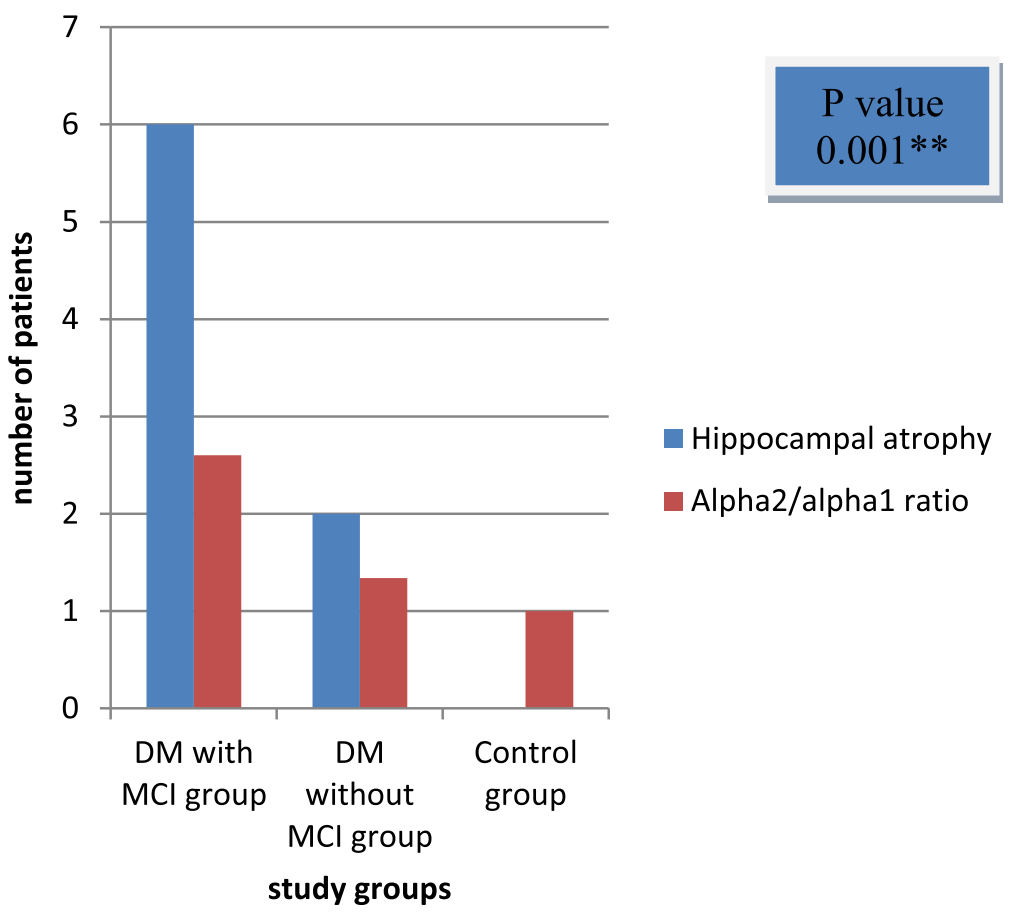

Fig. 2 Distribution of hippocampal atrophy and alpha 2/alpha 1 ratio among the study groups. $\mathrm{DM}=$ diabetes mellitus, $\mathrm{MCl}=\mathrm{mild}$ cognitive impairment

alpha 1 is related to hippocampal atrophy (Rossini et al. 2006). In the current study, alpha 2/alpha 1 power ratio was found significant among patient with hippocampal atrophy and this was supported by Moretti et al. (2011) and Frisoni (2012).

Finally, type $2 \mathrm{DM}$ was suggested by Roberts et al. (2014) to be the factor of increasing the risk of cognitive impairment acceleration and development of MCI into dementia, furthermore resulting in hippocampal atrophy which may end in QEEG changes (Ganguli et al. 2004; Hussain 2007; Xu et al. 2010). But unfortunately, there were no available data about the effect of DM on QEEG. So the current study points out that DM could directly result in QEEG changes as well as resulting in hippocampal atrophy which may open the door to enrich the idea for further studies to consider using QEEG as an alternative predictor of hippocampal atrophy for mild cognitive impairment.

\section{Conclusions}

Type 2 DM was suggested to increase the risk of cognitive impairment. The cognitive impairment in patients with diabetes mellitus was associated with changes in hippocampal volume and QEEG changes. Follow-up assessment of cognitive function of diabetic patients is recommended to detect early cognitive dysfunction, and proper glycemic control may have a good prognostic value in cognitive performance in diabetic patients.

\section{Funding}

The authors were responsible for the cost of this study including the design of the study and collection, analysis, and interpretation of data and in writing the manuscript.

Availability of data and materials

The data can be publicly available at the Faculty of Medicine, Suez Canal University.

Authors' contributions

AA carried out the study conception and design and coordination of the study and drafted the manuscript. AY contributed to the analysis and interpretation of data and helped to draft the manuscript. AR participated in the study design and the sequence alignment and helped to draft the manuscript. EM participated in the study design and coordination and helped to draft the manuscript. SO carried out the design of the study, participated in the acquisition of data, and performed the statistical analysis. All authors read and approved the final manuscript.

Ethics approval and consent to participate

The study was approved by the Ethics Committee of Suez Canal Faculty of Medicine on April 14, 2015. The committee number is 2399. An informed consent was taken from all the participants in the study.

\section{Consent for publication}

All participants had signed an informed consent to participate and for the data to be published.

Competing interests

The authors declare that they have no competing interests. 


\section{Publisher's Note}

Springer Nature remains neutral with regard to jurisdictional claims in published maps and institutional affiliations.

Received: 2 October 2017 Accepted: 4 May 2018

Published online: 01 June 2018

\section{References}

Albert MS, DeKosky ST, Dickson D, Dubois B, Feldman HH, Fox NC, et al. The diagnosis of mild cognitive impairment due to Alzheimer's disease: recommendations from the National Institute on Aging-Alzheimer's Association workgroups on diagnostic guidelines for Alzheimer's disease. Alzheimers Dement. 2011:7:270-9.

Allen KV, Frier BM, Strachan MW. The relationship between type 2 diabetes and cognitive dysfunction: longitudinal studies and their methodological limitations. Eur J Pharmacol. 2004;490:169-75.

American Psychiatric Association (APA). Diagnostic and statistical manual of mental disorders, fifth ed. Arlington: American Psychiatric Publishing; 2013.

Beck AT, Steer RA, Brown GK. Manual for Beck Depression Inventory II (BDI-II) San Antonio: psychology corporation. 1996.

Biessels GJ, Staekenborg S, Brunner E, Brayne C, Scheltens P. Risk of dementia in diabetes mellitus: a systematic review. Lancet Neurol. 2006;5:64-74.

Biessels GJ, Staekenborg S, Patel B, Tang MX, Manly JJ, Mayeux R. Relation of diabetes to mild cognitive impairment. Arch Neurol. 2007:64:570-5.

Das SK, Bose P, Biswas A, Dutt A, Banerjee TK, Hazra A, et al. An epidemiologic study of mild cognitive impairment in Kolkata, India. Neurology. 2007:68:2019-26.

Folstein MF, Folstein SE, McHugh PR. Minimental state. A practical method for grading the cognitive state of patients for the clinician. J Psychiatr Res. 1975; 12:189-98.

Frisoni GB. Alzheimer disease: biomarker trajectories across stages of Alzheimer disease. Nat Rev Neurol. 2012;8:299-300.

Ganguli M, Dodge HH, Shen C, Dekosky ST. Mild cognitive impairment, amnestic type: an epidemiologic study. Neurology. 2004;63:115-21.

Holschneider DP, Leuchter AF, Scremin OU, Treiman DM, Walton NW. Effects of cholinergic deafferentation and NGF on brain electrical coherence. Brain Res Bull. 1998;45:531-41.

Hussain $\mathrm{H}$. Conversion from subtypes of mild cognitive impairment to Alzheimer dementia. Neurology. 2007;69:409.

Ingber L, Nunez PL. Neocortical dynamics at multiple scales: EEG standing waves, statistical mechanics and physical analogs. Math Biosci. 2011;229:160-73.

Jelic V, Johansson SE, Almkvist JP, Nordberg A, Winblad B, et al. Quantitative electroencephalography in mild cognitive impairment: longitudinal changes and possible prediction of Alzheimer's disease. Neurobiol Aging. 2000;21:533-40

Klimesch W, Sauseng P, Gerloff C. Enhancing cognitive performance with repetitive transcranial magnetic stimulation at human individual alpha frequency. Eur J Neurosci. 2003;17:1129-33.

Klimesch W, Sauseng P, Hanslmayr S. EEG alpha oscillations: the inhibition timing hypothesis. Brain Res Rev. 2007:53:63-88.

Kodl CT, Seaquist ER. Cognitive dysfunction and diabetes mellitus. Endocr Rev. 2008:29:494-511.

McKhann GM, Knopman DS, Chertkow H, Hyman BT, Jack CR, Kawas CH, et al. The diagnosis of dementia due to Alzheimer's disease: recommendations from the National Institute on Aging-Alzheimer's Association workgroups on diagnostic guidelines for Alzheimer's disease. Alzheimers Dement. 2011;7:263-9.

Moretti DV, Frisoni GB, Fracassi C, Pievani M, Geroldi C, Binetti G, et al. MCl patients' EEGs show group differences between those who progress and those who do not progress to AD. Neurobiol Aging. 2011;32:563-71.

Moretti DV, Miniussi C, Frisoni GB, Zanetti O, Binetti G, Geroldi C, et al. Vascular damage and EEG markers in subjects with mild cognitive impairment. Clin Neurophysiol. 2007;118(8):1866-76.

Nicolelis MAL, Fanselow EE. Dynamic shifting in thalamocortical process during different behavioral states. R Soc. 2002;357:1753-8.

O'Donnell P, Grace AA. Synaptic interactions among excitatory afferents to nucleus accumbens neurons: hippocampal gating of prefrontal cortical input. J Neurosci. 1995;15:3622-39.

Petersen RC, Negash S. Mild cognitive impairment: an overview. CNS Spectrums. 2008; $13: 45-53$

Prichep LS. Quantitative EEG and electromagnetic brain imaging in aging and in the evolution of dementia. Ann N Y Acad Sci. 2007;1097:156-67.

Pruessner JC, Li LM, Serles W, Pruessner M, Collins DL, Kabani N, et al. Volumetry of hippocampus and amygdala with high-resolution MRI and three- dimensional analysis software: minimizing the discrepancies between laboratories. Cereb Cortex. 2000;10:433-42.

Roberts RO, Knopman DS, Geda YE, Baertlein L, Cha RH, Pankratz VS, et al. Association of diabetes with amnestic and nonamnestic mild cognitive impairment. Alzheimers Dement. 2014;10:18-26.

Rossini PM, Del Percio C, Pasqualetti P, Cassetta E, Binetti G, Forno D, et al. Conversion from mild cognitive impairment to Alzheimer's disease is predicted by sources and coherence of brain electroencephalography rhythms. Neuroscience. 2006;143:793-803.

Sarter M, Bruno JP. Cognitive functions of cortical cholinergic: toward a unifying hypothesis. Brain Res Rev. 1997;23:329-43.

Sarter M, Bruno JP. Abnormal regulation of corticopetal cholinergic neurons and impaired information processing in neuropsychiatric disorders. Trends Neurosci. 1999;22:67-74.

Sarter M, Bruno JP. Cortical cholinergic inputs mediating arousal, attentional processing and dreaming: differential afferent regulation of the basal forebrain by telencephalic and brainstem afferents. Neuroscience. 2000;95:933-52.

Sharbrough F, Chatrian G-E, Lesser RP, Luder H, Nuwer M, Picton TW, et al. American Electroencephalographic Society guidelines for standard electrode position nomenclature. J Clin Neurophysiol. 2002;8:1991-2002.

Tsanov M, Wrigh N, Van SD, Erichsen JT, Aggleton JP, O'Mara SM. Hippocampal inputs mediate theta-related plasticity in anterior thalamus. Neuroscience. 2011;187:52-62.

Xu W, Caracciolo B, Wang HX, Winblad B, Bachman L, Qiu C, et al. Accelerated progression from mild cognitive impairment to dementia in people with diabetes. Diabetes. 2010;59:2928-35.

\section{Submit your manuscript to a SpringerOpen ${ }^{\circ}$ journal and benefit from:}

- Convenient online submission

- Rigorous peer review

- Open access: articles freely available online

- High visibility within the field

- Retaining the copyright to your article

Submit your next manuscript at $\boldsymbol{\nabla}$ springeropen.com 